\title{
Highly Enantioselective Cyanosilylation of Aldehydes Catalyzed by a Chiral Oxazaborolidinium Ion.
}

\author{
Do Hyun Ryu and E. J. Corey* \\ Department of Chemistry and Chemical Biology \\ Harvard University, Cambridge, Massachusetts, 02138, USA
}

\section{$\underline{\text { Supplementary Materials }}$}

Materials and Methods. Thin-layer chromatography (TLC) was performed using E. Merck silica gel $60 \mathrm{~F}_{254}$ precoated plates $(0.25 \mathrm{~mm})$. Flash chromatography was performed using Baker silica gel (40 $\mu \mathrm{m}$ particle size). NMR spectra were recorded on Varian Innova-500, or Mercury400 instruments and calibrated using residual undeuterated solvent as an internal reference. IR spectra were recorded on Avatar 360 FT-IR spectrometer. Gas chromatography (GC) analyses were performed on Hewlett-Packard 6850 Series GC System equipped with flame ionization detector using a J \& W Scientific Cyclosil-B (30 m x $0.25 \mathrm{~mm}$ ) or Chiraldex $\gamma$-TA (30 m x 0.25 mm) column. Toluene was distilled from sodium. Trimethylsilyl cyanide, benzaldehyde, $o$ tolualdehyde, anisaldehyde and pivaldehyde were distilled from calcium hydride. Cyclohexanecarboxaldehyde and heptaldehyde were distilled from magnesium sulfate.

General Procedure for the Preparation and Use of Chiral Catalyst. A 100-mL, two-necked, round-bottomed flask equipped with a stir bar, a glass stopper and a 50-mL pressure-equalizing addition funnel (containing a cotton plug and ca. $10 \mathrm{~g}$ of $4 \AA$ molecular sieves, ${ }^{1}$ and functioning as a Soxhlet extractor) fitted on top with a reflux condenser and a nitrogen inlet adaptor was charged with $(S)-(-)-\alpha, \alpha$-dimexyl-2-pyrrolidinemethanol ${ }^{2}(188.0 \mathrm{mg}, 0.608 \mathrm{mmol})$, tri- $o$ tolylboroxine $^{3}(71.4 \mathrm{mg}, 0.202 \mathrm{mmol})$ and $25 \mathrm{~mL}$ of toluene. The resulting solution was heated

\footnotetext{
${ }^{1}$ Molecular sieves (pellets) were dried in vacuo at $\mathrm{ca} .200{ }^{\circ} \mathrm{C}$ with a gas burner for $10 \mathrm{~min}$ prior to use.

${ }^{2}$ Mathre, D. J.; Jones, T. K.; Xavier, L. C.; Blacklock, T. J.; Reamer, R. A.; Mohan, J. J.; Jones, E. T. T.; Hoogsteen, K.; Baum, M. W.; Grabowski, E. J. J. J. Org. Chem.1991, 56, 751-762.

${ }^{3}$ Corey, E. J.; Shibata, T.; Lee, T. W. J. Am. Chem. Soc. 2002, 124, 3808-3809.
} 
to reflux (bath temperature $\sim 145^{\circ} \mathrm{C}$ ). After $3 \mathrm{~h}$, the reaction mixture was cooled to $\mathrm{ca} .60^{\circ} \mathrm{C}$ and the addition funnel and the condenser were quickly replaced with a short-path distillation head. The mixture was concentrated by distillation (air-cooling) to a volume of $c a$. $5 \mathrm{~mL}$. This distillation protocol was repeated three times by re-charging with $3 \times 5 \mathrm{~mL}$ of toluene. The solution was then allowed to cool to room temperature to give the oxazaborolidine precursor solution $(0.608 \mathrm{mmol})$ in toluene $(c a .5 \mathrm{~mL})$. To the solution at $-25{ }^{\circ} \mathrm{C}$ was added trifluoromethanesulfonimide $(0.20 \mathrm{M}$ solution in toluene, freshly prepared, $2.5 \mathrm{~mL}, 0.5 \mathrm{mmol})$ dropwise. After $10 \mathrm{~min}$ at $-25{ }^{\circ} \mathrm{C}$, a colorless homogeneous catalyst solution was ready for use in the cyanosilylation reactions.

To triphenylphosphine oxide $(293 \mathrm{mg}, 1.05 \mathrm{mmol})$ was added a catalyst solution in toluene (7.5 $\mathrm{mL}$ ) at $0{ }^{\circ} \mathrm{C}$ and it was stirred for $5 \mathrm{~min}$ until triphenylphosphine oxide dissolved in toluene completely. Trimethylsilyl cyanide $(0.752 \mathrm{~mL}, 5.64 \mathrm{mmol})$ was added to the catalyst solution in one portion and an aldehyde $(5 \mathrm{mmol})$ solution in toluene $(3 \sim 5 \mathrm{~mL})$ was dropwise added to the solution for $1 \mathrm{hr}$. Then the reaction mixture was stirred at $0{ }^{\circ} \mathrm{C}$ for the time indicated in Table 1 and monitored by ${ }^{1} \mathrm{H}$ NMR or TLC.

Method 1 (Direct hydrolysis to cyanohydrin): When it was judged to be complete, $2 \mathrm{~N} \mathrm{HCl}$ (5 $\mathrm{mL})$ and ethyl acetate $(5 \mathrm{~mL})$ were added and the resulting mixture was stirred vigorously for 2 hr. The aqueous layer was extracted with EtOAc $(3 \times 5 \mathrm{~mL})$. The combined extract was dried over anhydrous $\mathrm{Na}_{2} \mathrm{SO}_{4}$ and evaporated, affording a residue that was purified by flash chromatography ${ }^{4}$ to obtain pure cyanohydrins.

Method 2 (Isolation of TMS protected cyanohydrin): When it was judged to be complete, volatile materials were evaporated in vacuo and water $(5 \mathrm{~mL})$ and pentane $(5 \mathrm{~mL})$ were added.

\footnotetext{
4 After elution of the cyanohydrin, the ligand-containing fractions were eluted with $10 \% \mathrm{MeOH}_{-} \mathrm{CH}_{2} \mathrm{Cl}_{2}$ and concentrated in vacuo. This material was dissolved in diethyl ether and hydrolyzed by stirring with aqueous $2 \mathrm{~N}$ $\mathrm{NaOH}$ solution for $2 \mathrm{~h}$. The organic phase was collected, concentrated and purified by column chromatography (elution with EtOAc) to afford pure ligand (95-97\% recovery).
} 
The aqueous layer was extracted with pentane $(3 \mathrm{x} 5 \mathrm{~mL}) .^{5}$ The combined extract was dried over anhydrous $\mathrm{Na}_{2} \mathrm{SO}_{4}$, cooled down to $-20{ }^{\circ} \mathrm{C}$ to remove residual triphenylphosphine oxide, filtered through glass filter and concentrated to afford the corresponding TMS protected cyanohydrin which was pure enough for the most purposes.

The corresponding racemic products for the determination of enantioselectivity were prepared by using ethylaluminum dichloride $(10 \mathrm{~mol} \%)$ as a Lewis acid catalyst.

\section{Determination of Enantioselectivity and Absolute Configuration of the Cyanohydrins}

\section{Reported in Tables 1.}

Table 1, entry 1: Enantioselectivity of TMS ether was determined by GC analysis $(\boldsymbol{\gamma}$-TA, 120 ${ }^{\circ} \mathrm{C}, 22 \mathrm{psi}$ ); retention times: 10.53 (major), $10.88 \mathrm{~min}$ (minor). The absolute configuration was determined by the sign of optical rotation: $[\alpha]_{\mathrm{D}}^{23}+45.3\left(c 2.0, \mathrm{CHCl}_{3}, 95 \%\right.$ ee $)$. [lit. $[\alpha]_{\mathrm{D}}^{24}+36.8$ (c 2.0, $\mathrm{CHCl}_{3}$ ) for $R$-enantiomer in $85 \%$ ee]; Hayashi, M.; Miyamoto, Y.; Inoue, T.; Oguni, N. $J$. Org. Chem. 1993, 58, 1515-1522.

Table 1, entry 2: Enantioselectivity of TMS ether was determined by GC analysis (Cyclosil B, $150{ }^{\circ} \mathrm{C}, 25 \mathrm{psi}$ ); retention times: 23.44 (minor), 24.45 min (major). The absolute configuration was determined by the sign of optical rotation: $[\alpha]_{\mathrm{D}}^{23}+39.9\left(\right.$ c 2.0, $\mathrm{CHCl}_{3}, 91 \%$ ee $)$. [lit. $[\alpha]_{\mathrm{D}}$ $+21.3\left(c\right.$ 1.0, $\mathrm{CHCl}_{3}$ ) for $R$-enantiomer in 51\% ee]; Matthews, B. R.; Jacson, W. R.; Jayatilake, G. S.; Wilshire, C.; Jacobs, H. A. Aust. J. Chem. 1988, 41, 1697-1709.

Table 1, entry 3: Enantioselectivity was determined by conversion to the $(R)$-MTPA ester derivative and ${ }^{1} \mathrm{H}$ NMR integration $\left(500 \mathrm{MHz} \mathrm{CDCl}_{3}\right): \delta 3.57(\mathrm{~d}, 3 \mathrm{H}, J=1.0 \mathrm{~Hz}$, major), 3.45 (d, $3 \mathrm{H}, J=0.5 \mathrm{~Hz}$, minor). The absolute configuration was assigned by the sign of optical

\footnotetext{
5 After pentane extraction, the aqueous solution was treated with aqueous $2 \mathrm{~N} \mathrm{NaOH}$ solution and extracted with diethyl ether. The combined extract was dried over $\mathrm{Na}_{2} \mathrm{SO}_{4}$, concentrated to afford a mixture of ligand and triphenylphosphine oxide. Triphenylphosphine oxide was removed by treatment with hexanes to give pure ligand (95-97\% recovery).
} 
rotation: $[\alpha]_{\mathrm{D}}^{23}+43.2\left(c 2.0, \mathrm{CHCl}_{3}, 90 \%\right.$ ee $)$. [lit. $[\alpha]_{\mathrm{D}}^{24}+41.7\left(c 1.4, \mathrm{CHCl}_{3}\right)$ for $R$-enantiomer in 91\% ee]; Hayashi, M.; Miyamoto, Y.; Inoue, T.; Oguni, N. J. Org. Chem. 1993, 58, 15151522.

Table 1, entry 4: Enantioselectivity of TMS ether was determined by GC analysis ( $\gamma$-TA, 140 ${ }^{\circ} \mathrm{C}, 22 \mathrm{psi}$ ); retention times: 27.04 (minor), 27.64 min (major). The absolute configuration was determined by the sign of optical rotation: $[\alpha]_{\mathrm{D}}^{23}+31.5\left(c 1.0, \mathrm{CHCl}_{3}, 97 \%\right.$ ee $)$. $\left[\right.$ lit. $[\alpha]_{\mathrm{D}}+16.6(c$ 0.8, $\mathrm{CHCl}_{3}$ ) for $R$-enantiomer in $52 \%$ ee]; Matthews, B. R.; Jacson, W. R.; Jayatilake, G. S.; Wilshire, C.; Jacobs, H. A. Aust. J. Chem. 1988, 41, 1697-1709.

Table 1, entry 5: Enantioselectivity of TMS ether was determined by GC analysis (Cyclosil B, $90{ }^{\circ} \mathrm{C}, 25 \mathrm{psi}$ ); retention times: 36.59 (minor), $37.27 \mathrm{~min}$ (major). The absolute configuration was determined by the sign of optical rotation: $[\alpha]_{\mathrm{D}}^{23}+8.2\left(c 2.0, \mathrm{CHCl}_{3}, 90 \%\right.$ ee $)$. [lit. $[\alpha]^{24}{ }_{\mathrm{D}}$ +6.1 (c 3.8, $\mathrm{CHCl}_{3}$ ) for $R$-enantiomer in 65\% ee]; Hayashi, M.; Miyamoto, Y.; Inoue, T.; Oguni, N. J. Org. Chem. 1993, 58, 1515-1522.

Table 1, entry 6: Enantioselectivity of TMS ether was determined by GC analysis $(\gamma-\mathrm{TA}, 70$ ${ }^{\circ} \mathrm{C}, 22 \mathrm{psi}$ ); retention times: 8.12 (major), $8.38 \mathrm{~min}$ (minor). The absolute configuration was determined by the sign of optical rotation: $[\alpha]_{\mathrm{D}}^{23}+17.5\left(c 1.0, \mathrm{CHCl}_{3}, 91 \%\right.$ ee $)$. [lit. $[\alpha]_{\mathrm{D}}^{24}+14.5$ $\left(c 1.0, \mathrm{CHCl}_{3}\right.$ ) for $R$-enantiomer in 70\% ee]; Hayashi, M.; Miyamoto, Y.; Inoue, T.; Oguni, N. $J$. Org. Chem. 1993, 58, 1515-1522.

Table 1, entry 7: Enantioselectivity of TMS ether was determined by GC analysis $(\gamma-\mathrm{TA}, 100$ ${ }^{\circ} \mathrm{C}, 22 \mathrm{psi}$ ); retention times: 11.20 (minor), $13.11 \mathrm{~min}$ (major). The absolute configuration was determined by the sign of optical rotation: $[\alpha]_{\mathrm{D}}^{23}+12.4\left(c 2.0, \mathrm{CHCl}_{3}, 91 \%\right.$ ee $)$. [lit. $[\alpha]_{\mathrm{D}}^{21}-13.3(c$ 1.0, $\mathrm{CHCl}_{3}$ ) for $S$-enantiomer in 98\% ee]; Hamashima, Y.; Swada, D.; Kanai, M.; Shibasaki, M. J. Am. Chem. Soc. 1999, 121, 2641-2642. 


\section{Physical Data of the Cyanohydrins:}

(R)-2-Hydroxy-2-phenylacetonitrile (Table 1, entry 1). The physical and spectral data were identical to those previously reported for this compound ${ }^{6}:{ }^{1} \mathrm{H}$ NMR $\left(500 \mathrm{MHz}, \mathrm{CDCl}_{3}\right) \delta 7.49-$ $7.51(\mathrm{~m}, 2 \mathrm{H}), 7.40-7.43(\mathrm{~m}, 3 \mathrm{H}), 5.50(\mathrm{~s}, 1 \mathrm{H}), 2.04$ (brs, $1 \mathrm{H}) ;{ }^{13} \mathrm{C} \mathrm{NMR}\left(125 \mathrm{MHz}, \mathrm{CDCl}_{3}\right)$ $\delta$ 135.2, 129.6, $129.0(\mathrm{x} 2), 126.6(\mathrm{x} 2), 118.9,63.3,18.6 ;[\alpha]_{\mathrm{D}}^{23}+45.3\left(c 2.0, \mathrm{CHCl}_{3}, 95 \%\right.$ ee) .

(R)-2-Hydroxy-2-o-tolylacetonitrile (Table 1, entry 2). ${ }^{1} \mathrm{H}$ NMR (400 MHz, $\left.\mathrm{CDCl}_{3}\right) \delta 7.57$ $(\mathrm{dd}, 1 \mathrm{H}, J=8.0,1.4 \mathrm{~Hz}$ ), 7.33 (ddd, $1 \mathrm{H}, J=8.0,8.0,1.4 \mathrm{~Hz}$ ), 7.27 (ddd, $1 \mathrm{H}, J=7.6,7.6,1.0$ $\mathrm{Hz}), 7.23(\mathrm{~d}, 1 \mathrm{H}, J=7.6 \mathrm{~Hz}), 5.61(\mathrm{~s}, 1 \mathrm{H}), 3.61$ (brs, $1 \mathrm{H}), 2.41(\mathrm{~s}, 3 \mathrm{H}) ;{ }^{13} \mathrm{C} \mathrm{NMR}(100 \mathrm{MHz}$, $\left.\mathrm{CDCl}_{3}\right) \delta 136.1,133.0,131.2,129.9,126.9,126.6,118.7,61.5,18.6$; FTIR (neat) 2361, 2340, 1021, 749; LRMS (CI) calcd for $\left[\mathrm{C}_{9} \mathrm{H}_{9} \mathrm{NO}\right]\left([\mathrm{M}]^{+}\right): 147$; found $147 ;[\alpha]_{\mathrm{D}}^{23}+39.9\left(c 2.0, \mathrm{CHCl}_{3}\right.$, $91 \%$ ee).

(R)-2-Hydroxy-2-(4-methoxyphenyl)acetonitrile (Table 1, entry 3). The physical and spectral data were identical to those previously reported for this compound ${ }^{6}:{ }^{1} \mathrm{H} \mathrm{NMR}\left(500 \mathrm{MHz}, \mathrm{CDCl}_{3}\right.$ ) d 7.45-7.48 (m, 2H), 6.94-6.97 (m, 2H), $5.49(\mathrm{~d}, 1 \mathrm{H}, J=6.5 \mathrm{~Hz}), 3.84(\mathrm{~s}, 3 \mathrm{H}), 2.42(\mathrm{~d}, 1 \mathrm{H}, J=$ $6.5 \mathrm{~Hz}) ;[\alpha]_{\mathrm{D}}^{23}+43.2\left(\right.$ c 2.0, $\mathrm{CHCl}_{3}, 90 \%$ ee $)$.

4-((R)-cyano(hydroxy)methyl)benzonitrile (Table 1, entry 4). The physical and spectral data were identical to those previously reported for this compound ${ }^{6}:{ }^{1} \mathrm{H} \mathrm{NMR}\left(500 \mathrm{MHz}, \mathrm{CDCl}_{3}\right) \delta$ $7.77(\mathrm{~d}, 2 \mathrm{H}, J=8.5 \mathrm{~Hz}), 7.69(\mathrm{~d}, 2 \mathrm{H}, J=9.0 \mathrm{~Hz}), 5.66(\mathrm{~d}, 1 \mathrm{H}, J=7.0 \mathrm{~Hz}), 2.80(\mathrm{~d}, 1 \mathrm{H}, J=6.5$ $\mathrm{Hz}) ;[\alpha]_{\mathrm{D}}^{23}+31.5\left(\right.$ c $\left.1.0, \mathrm{CHCl}_{3}, 97 \% \mathrm{ee}\right)$.

(R)-2-Cyclohexyl-2-hydroxyacetonitrile (Table 1, entry 5). The physical and spectral data were identical to those previously reported for this compound ${ }^{6}:{ }^{1} \mathrm{H}$ NMR $\left(500 \mathrm{MHz}, \mathrm{CDCl}_{3}\right) \delta$ $4.24(\mathrm{~d}, 1 \mathrm{H}, J=6.5 \mathrm{~Hz}), 3.74(\mathrm{brs}, 1 \mathrm{H}), 1.86(\mathrm{t}, 2 \mathrm{H}, J=13.0 \mathrm{~Hz}), 1.77-1.80(\mathrm{~m}, 2 \mathrm{H}), 1.67-1.73$ $(\mathrm{m}, 2 \mathrm{H}), 1.03-1.0(\mathrm{~m}, 5 \mathrm{H}) ;[\alpha]_{\mathrm{D}}^{23}+8.2\left(\right.$ c $2.0, \mathrm{CHCl}_{3}, 90 \%$ ee $)$.

\footnotetext{
${ }^{6}$ Hayashi, M.; Miyamoto, Y.; Inoue, T.; Oguni, N. J. Org. Chem. 1993, 58, 1515-1522.
} 
$(\boldsymbol{R})$-2-Hydroxy-3,3-dimethylbutanenitrile (Table 1, entry 6). The physical and spectral data were identical to those previously reported for this compound ${ }^{6}:{ }^{1} \mathrm{H}$ NMR $\left(500 \mathrm{MHz}, \mathrm{CDCl}_{3}\right) 4.13$ (s, 1H), 2.46 (brs, 1H), $1.08(\mathrm{~s}, 9 \mathrm{H}) ;[\alpha]_{\mathrm{D}}^{23}+17.5\left(\right.$ c 2.0, $\mathrm{CHCl}_{3}, 91 \%$ ee).

(R)-2-Hydroxyoctanenitrile (Table 1, entry 7). The physical and spectral data were identical to those previously reported for this compound ${ }^{7}{ }^{1} \mathrm{H} \mathrm{NMR}\left(400 \mathrm{MHz}, \mathrm{CDCl}_{3}\right) 4.48$ (brt, $1 \mathrm{H}, J=$ $6.8 \mathrm{~Hz}), 2.24$ (brs, 1H), 1.83-1.88 (m, 2H), 1.47-1.54 (m, 2H), 1.24-1.39 (m, 6H), 0.89 (t, 3H, $J=$ $7.2 \mathrm{~Hz}) ;[\alpha]_{\mathrm{D}}^{23}+12.4\left(\right.$ c 2.0, $\mathrm{CHCl}_{3}, 91 \%$ ee $)$.

\footnotetext{
${ }^{7}$ Hamashima, Y.; Swada, D.; Kanai, M.; Shibasaki, M. J. Am. Chem. Soc. 1999, 121, 2641-2642.
} 